\section{Brain injury and the eye}

\author{
Abstract \\ Visual loss associated with brain damage is \\ the single greatest cause of visual impairment \\ in children in developed countries. Damage \\ may occur in any of five separate visual \\ systems: primary visual cortex, visual \\ associative cortex area, optic radiations, optic \\ nerves, and visual attention pathways. \\ Improving our understanding of the \\ pathophysiology of these causes for visual loss \\ may lead to better rehabilitation and \\ educational strategies for these children. \\ Eye (2007) 21, 1285-1289; doi:10.1038/sj.eye.6702849
}

Keywords: visual loss; brain injury; visual disability

\section{Introduction}

Visual loss associated with brain damage is now the single greatest cause of visual impairment in children in developed countries. ${ }^{1-5}$ In some centres, it exceeds all causes of childhood ocular blindness combined. ${ }^{5}$ Historically, a wide range of aetiologies accounted for visual impairment associated with brain injury in children. These included hypoglycemia, ${ }^{6}$ haemodialysis, ${ }^{7}$ hydrocephalus, ${ }^{8-10}$ trauma $^{11-13}$ (accidental but much more commonly and tragically non-accidental), seizures, ${ }^{14}$ neurodegenerative disorders, ${ }^{15}$ encephalitis/meningitis, ${ }^{16-20}$ and other infectious disorders. ${ }^{21}$

However, at present, the single most common cause of visually significant brain injury in children is perinatal hypoxia ischemia. ${ }^{22-24}$ This is true for both term and preterm infants. The notion that neonatal brain injury is uniform and primarily due to acquired insults (especially birth asphyxia) is an oversimplification of a complex set of problems. ${ }^{25}$ The mechanisms accounting for these injuries are not limited to transient ischemia and reperfusion events. ${ }^{25}$ Nevertheless, there can be little doubt that the single most identifiable factor for the ever-increasing number of children with
CS Hoyt

hypoxic-ischemic encephalopathy is improved perinatal care and the resulting increased survival rates for very small, critically ill, preterm infants. ${ }^{26}$ A comparable improvement in the critical care and survival of brain-injured full-term infants further aggravates the problem.

A large proportion of the human brain's neural substance subserves vision. Damage to a number of different structures within the central nervous system can result in significant visual disability. However, the specific nature of the visual disability, its clinical manifestations, associated non-visual neurologic complications, as well as prognosis for some visual recovery varies greatly depending on the site(s) of brain injury. ${ }^{5}$ In turn, the vulnerability of specific sites of the brain to hypoxic-ischemic insult is closely linked to the age of the infant at the time of the insult. $^{25}$

Damage to any one or more of at least five separate visual systems may account for the visual disability of children with brain injury. These include the primary visual cortex, visual associative cortex area, optic radiations, optic nerves, and visual attention pathways.

\section{Visual primary cortex}

In term infants who sustain ischemic-hypoxic injury, neurons primarily in the deep grey nuclei and perirolandic cortex are most likely to be injured. ${ }^{25}$ The resulting pattern of injury classically has been described to be within the 'watershed zones' of the cerebral cortex. (That is, in the areas between the anterior and middle cerebral arteries' circulation and the area between the middle and posterior arteries' circulation). In contrast, other neurons seem to be uniquely resistant to hypoxic-ischemic changes (especially those expressing nitric oxide synthase) ${ }^{25}$ It is noteworthy that mature oligodendrocytes in term infants are much more resistant to hypoxia-ischemia than preoligodendrocytes and oligodendrocyte progenitor cells that are found in the immature brain. ${ }^{27}$

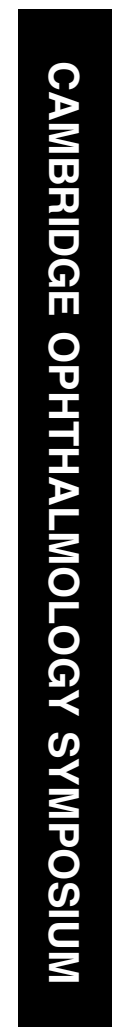

Department of Ophthalmology, University of California, San Francisco, CA, USA

Correspondence: CS Hoyt Department of

Ophthalmology, Smith-Kettlewell Eye Research Institute, University of California, San Francisco, CA 94143, USA

E-mail: choyt@itsa.ucsf.edu

Received: 7 March 2007 Accepted: 30 March 2007 
In term infants who experience hypoxia-ischemia discrete, often cystic infarctions in the 'water-shed' zones of the cortex are the typical resulting sites of injury. These infarctions are most likely to occur in the frontal and parieto-occipital regions. ${ }^{5}$ The resulting visual disabilities seen in these children usually are attributed to damage to the primary visual areas of the occipital cortex (thus the terms 'cortical blindness'). This seems intuitively obvious since primary visual processing takes place within the striate (occipital) cortex and damage to the occipital cortex is seen in varying degrees in nearly all of these infants. However, two notes of caution should be emphasized: (1) Only rarely does one see neuroimaging evidence of complete occipital cortex infarction in term infants with hypoxic-ischemic encephalopathy. Moreover, relative sparing of the most posterior areas (primary visual) with more severe involvement of the anterior areas (associative visual) is a frequent pattern of injury. (2) Perhaps, more importantly, there is poor correlation between the severity of apparent occipital cortex damage seen on CT or MRI and the severity of the functional visual disability seen in affected children. ${ }^{28-31}$

In most studies of term infants with hypoxic-ischemic encephalopathy and visual disability improvement in visual function is frequently observed over a period of several months or even a few years. ${ }^{5,24}$ There are several possible reasons why term infants with hypoxic-ischemic encephalopathy may show visual improvement over time. It may be simply that the normal maturation of visual systems that is seen in normal infants allows residual visual potential in these brain damaged children to become apparent over time. ${ }^{32}$ Another possible explanation is that the damage to the visual cortex is usually incomplete. Thus, residual function may simply reflect the still functioning portions of the visual cortex. $^{33}$

However, most investigators who have studied these children seem to believe that some unique mechanism involving 'plasticity' of the infant brain is an essential factor in the apparent visual 'recovery' that is described so frequently in these children., 28,34 This is in sharp contrast to the situation in adults where the consensus is that visual loss associated with damage to the visual cortex is permanent and irrepairable. ${ }^{35}$ The exception to this rule is the processing of motion. It has now been shown that visual motion processing in cortical area MT of the peristriate cortex will still occur, although less robustly than usual, after ablation of the primary visual cortex in adult nonhuman primates. ${ }^{36}$ This is probably the physiologic correlate of the 'Riddoch phenomena'.

George Riddoch, ${ }^{37}$ a captain in the Royal Army Medical Corps, described 10 British soldiers with occipital cortex injuries who were able to perceive motion within their scotomas. This study, performed during the first world war was ridiculed by authorities at that time. Nevertheless, Riddoch came to the prescient conclusion that 'movement may be recognized as a special visual perception separate and in addition to other perceptions'.

Evidence for plasticity of the retinogeniculate projections in infants is supported by experimental observations in newborn animals. Ablation of the visual cortex in infant cats results in an interesting series of central nervous system 'adaptations,' which may help explain the apparent visual improvement in term infants with hypoxic injury to the visual cortex. Lesions of the primary visual cortex in infant cats leads to significant changes in the organization of several portions of the visual system. There is a dramatic, severe retrograde degeneration of retinal ganglion cells with a $78 \%$ loss of retinal ganglion cells of the $X / \beta$ class. ${ }^{38,39}$ Of even more interest are the adaptative changes that take place in the cortical areas. Anatomical studies with both anterograde and retrograde tracing methods reveal increased projections from the retina through the thalamus to the posteromedial lateral suprasylvian extrastriate visual areas of the cortex following visual cortex ablation in neonatal cats. ${ }^{40-42}$ No such enhanced projections to the PMLS cortex is seen in cats who undergo ablation of the visual cortex as adults. Single-cell neurophysiologic studies indicate that physiologic compensation is present in PMLS. These cells develop visual receptive field properties although they do not acquire response properties of the normal striate cortex (high spatial frequency tuning and the low contrast threshold). ${ }^{43,44}$

Moore et $a l^{45}$ have documented a significant difference in visual recovery of infant $v s$ adult monkeys with visual cortex ablations but the precise anatomical correlates for this recovery have not yet been defined in monkeys. Whether a similar series of adaptations occurs in human term infants with visual cortex damage is not known. However, current fMRI, MEG, and EEG techniques could be utilised to study older children who suffered infantile visual cortex damage in an effort to see if enhanced activity of the PMLS occurs with visual stimulation.

\section{Associative visual cortex areas}

As was stated previously, the cortical damage in term infants from hypoxic-ischemic insult is rarely confined to just the primary visual cortex. Indeed, a significant subset of these children suffer insults primarily within the associative visual areas of the occipital cortex and/or portions of the temporal or parietal cortices. As Dutton and co-workers ${ }^{26}$ have pointed out, these children may have visual acuity and visual field loss coupled with specific visual disabilities attributed to damage to the dorsal stream system (parietal lobe) or ventral stream system (temporal lobe). Even more challenging are the 
children, who present with normal or slightly reduced acuities but with significant cognitive visual dysfunction. $^{31,46}$ These children are often misdiagnosed or even ignored because of the apparent contradictory findings of little or no visual acuity and field loss in the presence of significant and often ill-understood visual complaints. The associative visual cortex areas contribute a significant portion of the visual disability in a number of children with brain damage and visual disability.

\section{Optic radiations}

In sharp contrast to the pattern of brain injury resulting from hypoxia-ischemia in the term infant with the pathology concentrated in cortical areas, the preterm infant shows a completely different injury pattern. If hypoxia-ischemia occurs early in gestation and the baby is born prematurely, some oligodendrocytes and subplate neurons are lost. ${ }^{25}$ Subplate neurons appear only transiently during development but they play an important role in forming connections between the thalamus and visual cortex. ${ }^{47}$ As will be seen in a subsequent discussion, the interference with subplate neuron development may have a significant effect on visual attention mechanisms.

The clinical syndrome that results from neonatal periventricular white matter damage is referred to as periventricular leukomalacia (PVL). Affected children usually have a spastic diplegia due to the fact that the cortico-spinal pathways run through the periventricular white matter. Visual impairment is common in these children, usually manifesting as significant central visual loss coupled with an inferior visual field loss that is greater than the superior. ${ }^{48}$ Most authorities agree that potential for visual 'recovery' in these children is significantly less than in children with primary visual cortex damage. $5,23,24$ The reason for this has yet to be determined. Nevertheless, the tantalizing possibly is that damage to the optic radiations rather than the primary visual cortex precludes the anomalous projections of the retino-geniculate system to the posteromedial lateral sylvian cortex described in the infant visual cortex ablation experiments of Spear and co-workers. $^{38-44}$

\section{Optic nerve}

Optic nerve changes are frequently seen in association with either primary visual cortex injury in term infants or PVL in preterm infants. ${ }^{5,49}$ The exact frequency of optic nerve pathology in these disorders is a subject of debate. ${ }^{5,49}$ In the term infant with primary visual cortex injury optic atrophy is said to occur in less than $20 \%$ of cases. ${ }^{5,49}$ This is noteworthy. Recall that Spear and co-workers reported that following neonatal visual cortex ablation in cats there is a $78 \%$ loss of retinal ganglion cells of the $X / \beta$ class. In contrast, visual cortex ablation in adult cats results in only a $22 \%$ loss of $X / \beta$ cells. Theoretically, every child who suffers a significant neonatal visual cortex injury should reveal some degree of obvious optic atrophy. New scanning devices that provide details of the retinal nerve fibre layer loss might reveal a much higher frequency of optic atrophy in these children than is detected by ophthalmoscopic techniques.

Perhaps of more interest is the unique disc anomaly associated with some cases of PVL. In 1997, Jacobson and co-workers ${ }^{50}$ reported that a normal-sized optic disc with a large optic cup was a specific association seen in patients with PVL. Others have subsequently confirmed this interesting report. ${ }^{5,49}$ This optic disc change can mimic the changes seen in congenital glaucoma and is, therefore, of more than phenomenological interest. On the other hand, these disc changes seen in children with neonatal visual cortex damage as well as those with PVL reflect the primary 'upstream' insults with secondary transsynaptic degeneration of syndrome optic nerve fibres. The optic nerve changes are not the primary cause of the visual disability in these children.

\section{Visual attention mechanisms}

The apparent recovery of vision in some children with significant visual cortex damage has been discussed previously. A complete explanation of this observation has yet to be clearly articulated, but some reasonable explanations have been cited. The mechanism of recovery in cats that undergo neonatal visual cortex ablation seems a reasonable point of departure for further study. Less well recognized and more poorly understood are cases of children with significant visual problems and little or no evidence of injury to the optic radiations or primary visual cortex. In some of these cases, injury to the associative visual cortex may provide an explanation, but not in all of them. Moreover, there is very poor correlation between the clinical visual disability seen in preterm or term infants with brain injury and the extent of damage to the primary visual cortex and/or optic radiations seen on MRI or CT scan. ${ }^{28}$ It seems likely that the full extent of visual disability in these children cannot be understood without evaluating the visual attention mechanisms and damage to them in addition to assessing the degree of visual cortex and optic radiation damage.

The capacity of the visual system to process information about multiple objects at any given moment is limited. ${ }^{51}$ Because of limited processing resources, multiple objects present at the same time in the visual 
field compete for neural representation. The brain appears to handle this competition in two distinct ways: (1) a bottom-up stimulus-driven process, and (2) a top-down feedback attentional network. ${ }^{52,53}$ The visual attention network can be divided into a posterior system that primarily subserves visual spatial attention, and an anterior system that functions to select the stimulus of attention by providing 'executive functions'. The complete details of these areas have yet to be defined. However, non-human primate and human studies agree about their basic substraits. ${ }^{52,53}$

The anterior system involved in selection of stimuli (executive function@) depends to a great degree on the frontal cortex (frontal eye field and supplemental eye field areas). We have found that frontal cortex damage that is common in term infants with hypoxic-ischemic encephalopathy is inevitably accompanied by more severe visual dysfunction than in cases of isolated visual cortex damage without frontal cortex involvement. In addition, the globus pallidus, caudate, and putamen are essential, but other areas, especially the posterior thalamus, may also be involved. Recall the importance of subplate neurons in the pathophysiology of PVL and their vital role in providing connections between the thalamus and the cortex. Surely, their loss must contribute to the visual deficit in PVL.

The posterior system appears to involve the inferior parietal cortex (probably more predominantly on the right), superior colliculus and pulvinar. ${ }^{52,54}$ Involvement of the posterior parietal cortex in term infants with visual cortex injury adds an additional disability by interfering with this intentional system. I would suggest that in children with both PVL or primary cortex injury, the visual attention mechanism systems should be carefully evaluated on neuroimaging studies to ascertain potential damage of them. Failure to do so will underestimate the visual insult and disability in many children.

\section{Conclusion}

Brain injury is the leading cause of 'blindness' in children in the developed world. Recent advances in our understanding of the neuropathology of infantile brain injury coupled with advances in prevention and treatment of the same provide hope that this problem can be reduced in its impact in the very near future. ${ }^{25}$ In the meantime, there is much to be learned about the underlying mechanisms responsible for visual disability and potential recovery in these children. Improving our understanding may lead to better rehabilitation and education strategies for these children. At the very least, it would allow us to provide a more accurate and complete description of the problems facing these children. They deserve no less.

\section{References}

1 Foster A. Childhood blindness. Eye 1988; 2(suppl): 27-36.

2 Goggin M, O'Keefe M. Childhood blindness in the Republic of Ireland: a national survey. Br J Ophthalmol 1991; 75: 425-429.

3 Rosenberg T, Flage T, Hansen E. Incidence of registered visual impairment in the Nordic child population. $\mathrm{Br} \mathrm{J}$ Ophthalmol 1996; 80: 49-53.

4 Rogers M. Vision impairment in Liverpool: prevalence and morbidity. Arch Dis Child 1996; 74: 299-303.

5 Hoyt CS. Visual function in the brain-damaged child. Eye 2003; 17: 369-384.

6 Mukamel M, Weitz R, Nissenkorn I. Acute cortical blindness associated with hypoglycemia. J Pediatr 1981; 98: 583-584.

7 Moel DI, Kwun Y. Cortical blindness as a complication of hemodialysis. J Pediatr 1980; 97: 110-114.

8 Lorber J. Recovery of vision following prolonged blindness in children with hydrocephalus or following pyogenic meningitis. Clin Pediatr 1967; 6: 699-703.

9 Arroyo HA, Jan JE, McCormick AQ, Farrell K. Permanent visual loss after shunt malfunction. Neurology 1985; 35: 25-29.

10 Corbett JJ. Neuro-ophthalmologic complications of hydrocephalus and shunting procedures. Sem Neurol 1986; 6: 111-123.

11 Griffith JF, Dodge PR. Transient blindness following head injury in children. N Eng J Med 1968; 278: 648-651.

12 Eldridge PR, Punt JA. Transient traumatic cortical blindness in children. Lancet 1988; 1: 815-816.

13 Han DP, Wilkinson WS. Late ophthalmic manifestations of the shaken baby syndrome. J Pediatr Ophthalmol Strabismus 1990; 4: 108-113.

14 Kosnik E, Paulson GW, Laguan JF. Postictal blindness. Neurology 1976; 26: 248.

15 Acer TE, Cooper WC. Cortical blindness secondary to bacterial meningitis. Am J Ophthalmol 1965; 59: 226-229.

16 Ackroyd RS. Cortical blindness following bacterial meningitis: case report with reassessment of prognosis and etiology. Dev Med Child Neurol 1984; 26: 227-230.

17 Newton NL, Reynolds JD, Woody RC. Cortical blindness following Hemophilus influenzae meningitis. Ann Ophthalmol 1985; 17: 193-194.

18 Smith JL, Landing BH. Clinical and pathological aspects of influenzae meningitis. J Neuropathol Exp Neurological 1975; 32: 287-298.

19 Tepperberg J, Nussbaum D, Feldman F. Cortical blindness following meningitis due to Hemophilus influenzae type B. J Pediatr 1977; 91: 434-436.

20 El Azazi M, Malm G, Forsgren M. Late ophthalmologic manifestations of neonatal herpes simplex virus infection. Am J Ophthalmol 1990; 109: 1-7.

21 Bondi FS. The incidence and outcome of neurological abnormalities in childhood cerebral malaria: A long-term follow-up of 62 survivors. Trans R Soc Trop Med Hyg 1992; 86: 17-19.

22 Pike MG, Holmstrom G, de Vries LS. Patterns of visual impairment associated with lesions of the preterm infant brain. Dev Med Child Neurol 1994; 36: 849-862.

23 Eken P, de Vries LS, van der Graaf Y, Meiners LC, van Niuewenhuizen O. Hemorrhagic- ischemic lesions of the neonatal brain: Correlation between cerebral visual impairment, neurodevelopmental outcomes, and MIR in infancy. Dev Med Child Neurol 1995; 37: 41-55. 
24 Huo R, Burden S, Hoyt CS, Good WV. Chronic cortical visual impairment in children: etiology, prognosis, and associated neurological deficits. Br J Ophthalmol 1999; 83: 670-675.

25 Ferreiro DM. Neonatal brain injury. NEJM 2004; 351: 1985-1995.

26 Dutton GN, McKillop ECA, Saidkasimova A. Visual problems as a result of brain damage in children. $\mathrm{Br} J$ Ophthalmol 2006; 90: 932-933.

27 Haynes RL, Folkerth RD, Keefe RJ. Oxidative injury to premyelinating oligodendrocytes in periventricular leukomalacia. J Neuropathol Exp Neurol 2003; 62: 441-450.

28 Lambert SR, Hoyt CS, Jan JE, Barkovich JA, Flodmark O. Visual recovery from hypoxic cortical blindness during childhood. Arch Ophthalmol 1987; 105: 1371-1377.

29 Casteels I, Demaerel P, Spileers W, Lagae L, Missotten L, Casaer P. Cortical visual impairment following perinatal hypoxia: clinicoradiologic correlation using magnetic resonance imaging. J Pediatr Ophthalmol 1997; 34: 297-305.

30 Cioni G, Fazzi B, Ipata AE, Canapicchi R, van Hof-van Duin J. Correlation between cerebral visual impairment and magnetic resonance imaging in children with neonatal encephalopathy. Dev Med Child Neurol 1996; 38: 120-133.

31 Lowery RS, Atkinson D, Lambert SR. Cryptic visual impairment in children. Br J Ophthalmol 2006; 90: 960-963.

32 Hoyt CS, Nickel BL, Billson FA. Ophthalmological examination of the infant: developmental aspects. Surv Ophthalmol 1982; 26: 177-189.

33 Whiting S, Jan JE, Wong PK. Permanent cortical visual impairment in children. Dev Med Child Neurol 1985; 27: 730-739.

34 Good WV, Jan JE, deSa L, Barkovich JA, Groenveld M, Hoyt CS. Cortical visual impairment in children. Surv Ophthalmol 1994; 38: 351-364.

35 Holmes G. The Ferrier lecture. The organization of the visual cortex in man. Proc $R$ Soc L 1945; 132: 348-361.

36 Rodman HR, Gross CG, Albright TD. Afferent basis of visual response properties in area MT of the macaque. I. Effects of striate cortex removal. J Neurosi 1989; 9: 2033-2050.

37 Riddoch G. Dissociation of visual perceptions due to occipital injury with a special reference of movement. Brain 1917; 40: 15-57.

38 Callahan EC, Tong L, Spear PD. Critical period for the marked loss of retinal X-cells following visual cortex damage in cats. Brain Res 1984; 323: 302-306.

39 Tong L, Spear PD, Kalil RE, Callahan EC. Loss of retinal $\mathrm{X}$-cells in cats with neonatal or adult visual cortex damage. Science 1982; 216: 72-75.
40 Spear PD, Kalil RE, Tong L. Functional compensation in lateral suprasylvian visual area following neonatal visual cortex removal in cats. J Neurophysiol 1980; 43: 851-869.

41 Spear PD, Baumann TP. Neurophysiological mechanisms of recovery from visual cortex damage in cats: properties of lateral suprasylvian visual area neurons following behavioral recovery. Exp Brain Res 1979; 35: 177-192.

42 Spear PD, Tong L, McCall MA. Functional influence of areas 17,18 , and 19 on lateral suprasylvian cortex in kittens and adult cats: implications for compensation following early visual cortex damage. Brain Res 1988; 447: 79-91.

43 Guido W, Spear PD, Tong L. How complete is physiological compensation in extrastriate cortex after visual cortex damage in kittens? Exp Brain Res 1992; 91: 455-466.

44 Spear PD. Plasticity following neonatal visual cortex damage in cats. Can J Physiol Pharmacol 1995; 73: 1389-1397.

45 Moore T, Rodman HR, Repp AB, Gross CG, Mezrich RS. Greater residual vision in monkeys after striate cortex damage in infancy. J Neurophysiol 1996; 76: 3928-3933.

46 Dutton GM, Saaed A, Fahad B. The association of binocular lower visual field impairment, impaired simultaneous perception, disordered visual guided motion, and inaccurate saccades in children with cerebral visual dysfunction - a retrospective observational study. Eye 2004; 18: $27-34$

47 Kanold PO, Kara P, Reid RC, Schatz CJ. Role of subplate neurons in functioning maturation of visual cortical columns. Science 2003; 301: 521-525.

48 Jacobson L, Flodmark O, Martin L. Visual field defects in prematurely born patients with white matter damage of immaturity. Acta Ophthalmol 2006; 84: 357-362.

49 Brodsky MC, Fray KJ, Glasier CM. Perinatal cortical and subcortical visual loss: mechanism of injury and associated ophthalmologic signs. Ophthalmology 2003; 109: 85-94.

50 Jacobson L, Hellstrom A, Flodmark O. Large cups in normal-sized optic discs: a variant of optic nerve hypoplasia in children with periventricular leukomalacia. Arch Ophthalmol 1997; 115: 1263-1269.

51 Tsotsos JK. Analyzing vision at the complexity level. Behav Brain Sci 1990; 13: 423-469.

52 Kastner S, Ungerleider LG. Mechanisms of visual attention in the human cortex. Annu Rev Neurosci 2000; 23: 315-341.

53 Moore T. The neurobiology of visual attention: finding sources. Curr Opinion Neurobiol 2006; 16: 159-165.

54 Gaffan D, Homak J. Visual neglect in the monkey: representation and disconnection. Brain 1997; 120: 1647-1657. 